\title{
Hepatectomy for metachronous colorectal liver metastases following complete cytoreductive surgery and hyperthermic intraperitoneal chemotherapy for peritoneal metastases: a report of three cases
}

Kyoji Ito ${ }^{1}$, Nobuyuki Takemura ${ }^{1}$, Fuyuki Inagaki ${ }^{1}$, Fuminori Mihara' ${ }^{1}$ Toshiaki Kurokawaa ${ }^{1}$, Yoshimasa Gohda ${ }^{2}$, Tomomichi Kiyomatsu ${ }^{2}$, Hideaki Yano ${ }^{2}$ and Norihiro Kokudo ${ }^{1 *}$

\begin{abstract}
Background: Cytoreductive surgery (CRS) with hyperthermic intraperitoneal chemotherapy (HIPEC) for peritoneal metastasis (PM) from colorectal cancer (CRC) has been reported to substantially improve the prognosis and the quality of life of patients in comparison to systemic chemotherapy or palliative approaches. This study aimed to demonstrate the safety and feasibility of hepatectomy for metachronous liver metastases from CRC following CRS and HIPEC for PM on the basis of three case reports.
\end{abstract}

Case presentation: We describe three cases involving patients who underwent hepatectomy for metachronous liver metastases from CRC after CRS and HIPEC for PM. All patients underwent CRS and HIPEC after primary tumor resection, and hepatectomy was performed for the metachronous liver metastases after CRS and HIPEC. The hepatectomy procedures for cases 1, 2, and 3 were left hemihepatectomy and partial resection of S5, posterior sectionectomy, and left-lateral sectionectomy and partial resection of S5 and S8, respectively. Although adhesion of surrounding organs to the liver surface was observed on a broad level, dissections and hepatectomy could be performed safely. No recurrence was detected in cases 1 and 2 after hepatectomy. In case 3, liver metastases were detected from the time of the initial diagnosis of the primary tumor, and complete remission was achieved once with systemic chemotherapy. Although we performed hepatectomy for the recurrence of liver metastases after complete remission, early re-recurrence was observed after hepatectomy.

Conclusions: Hepatectomy for metachronous liver metastases after CRS and HIPEC for PM could be a multimodality treatment option for CRC recurrence.

Keywords: Colorectal cancer, Multi-modality treatment, Peritoneal metastases, Cytoreductive surgery, Hyperthermic intraperitoneal chemotherapy, Liver metastases, Hepatectomy

\footnotetext{
* Correspondence: nkokudo@hosp.ncgm.go.jp

${ }^{1}$ Hepato-Biliary-Pancreatic Surgery Division, Department of Surgery, National

Center for Global Health and Medicine, 1-21-1 Toyama, Shinjuku-ku, Tokyo

162-8655, Japan

Full list of author information is available at the end of the article
}

(c) The Author(s). 2019 Open Access This article is distributed under the terms of the Creative Commons Attribution 4.0 International License (http://creativecommons.org/licenses/by/4.0/), which permits unrestricted use, distribution, and reproduction in any medium, provided you give appropriate credit to the original author(s) and the source, provide a link to the Creative Commons license, and indicate if changes were made. The Creative Commons Public Domain Dedication waiver (http://creativecommons.org/publicdomain/zero/1.0/) applies to the data made available in this article, unless otherwise stated. 


\section{Background}

Distant metastases from colorectal cancer (CRC) to the peritoneum, i.e., peritoneal metastases (PM), develop in $10-25 \%$ of CRC patients $[1,2]$. Historically, PM from CRC were regarded as a terminal condition. Treatment was mainly based on palliative chemotherapy with poor longterm survival [2, 3], although some authors have reported a relatively favorable prognosis after simultaneous resection of PM and primary CRC in selected patients $[4,5]$.

Cytoreductive surgery (CRS) with hyperthermic intraperitoneal chemotherapy (HIPEC) for PM in patients with $\mathrm{CRC}$ has been shown to substantially improve the prognosis and quality of life compared with systemic chemotherapy or palliative approaches [6-12]. However, up to $80 \%$ of patients with PM originating from CRC who were treated with CRS and HIPEC are likely to experience recurrence $[13,14]$, and $10-20 \%$ of patients experience metastases to the liver $[15,16]$.

Treatments for colorectal liver metastases (CRLM) by multi-modality approaches, such as chemotherapy, surgery, and interventional radiology, have recently developed, and surgical resection may result in a 5-year survival rate of $35-45 \%[17,18]$. However, treatment strategies for metachronous liver metastases following CRS and HIPEC for PM have not been established and little is known about the safety and feasibility of hepatectomy following CRS and HIPEC for PM.

In this report, we describe three cases of metachronous liver metastasis of CRC treated by hepatectomy after CRS and HIPEC for PM.

\section{Case presentations}

\section{Perioperative management}

CRS and HIPEC were indicated for PM from CRC without any other distant metastases. After diagnosis of PM, exploratory laparoscopy was performed, and the size and distribution of the PM was confirmed. If PM was found on the small bowel mesentery, CRS and HIPEC were not indicated. Following neoadjuvant systemic chemotherapy (FOLFOX + cetuximab or bevacizumab) and intraabdominal chemotherapy (paclitaxel) for four cycles, CRS and HIPEC were performed. In CRS, the diseased peritoneum was stripped and organs with PM were resected. Specifically, the CRS procedures around the liver included peritonectomy of the bilateral diaphragm and hepatoduodenal ligament, lesser omentum resection, and ablation of the liver surface serosa (Fig. 1). The peritoneal cancer index (PCI) was used to assess the extent of peritoneal cancer throughout the peritoneal cavity [19]. The presence of residual disease was recorded using the completeness of cytoreduction (CC) score: $\mathrm{CC}-0$, no residual tumor; $\mathrm{CC}-1$, no residual tumor greater than $2.5 \mathrm{~mm}$; $\mathrm{CC}-2$, no residual tumor greater than $25 \mathrm{~mm}$; and CC-3, residual tumor greater than $25 \mathrm{~mm}$ [20].

In HIPEC, oxaliplatin $\left(300 \mathrm{mg} / \mathrm{m}^{2}\right)$ with $3 \mathrm{~L}$ of normal saline was heated to $42{ }^{\circ} \mathrm{C}$ and perfused in the abdomen for an hour using a circulating pump. After surgery, 5-fluorouracil (FU) $\left(300 \mathrm{mg} / \mathrm{m}^{2}\right)$ was administered intraabdominally through the abdominal drain tube from postoperative days (POD) 1 through 4 as early postoperative intraperitoneal chemotherapy to patients without contraindications, which included bleeding or abdominal distension. Adjuvant chemotherapy was not routinely performed after CRS and HIPEC.

The diagnosis of liver metastasis was performed by computed tomography or magnetic resonance imaging every 6 months after CRS and HIPEC. The indications for hepatectomy included technically resectable liver metastases that preserved a sufficient future liver remnant volume. There was no limit regarding the number or size of tumors when R0 resection was expected to be feasible. The characteristics of the following three cases are shown in Table 1.

\section{Case 1}

A 78-year-old woman underwent curative open right hemicolectomy for ascending colon cancer. Pathological
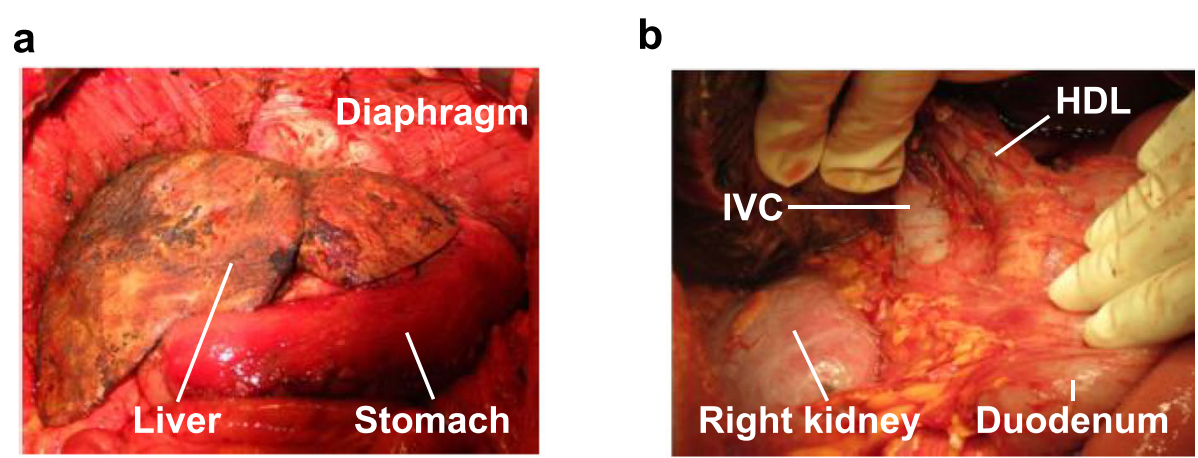

Fig. 1 Representative images of the CRS procedure around the liver. a The peritoneum of the bilateral diaphragm was stripped, and the liver surface serosa was ablated. $\mathbf{b}$ Peritonectomy of the hepatoduodenal ligament and retroperitoneum around the liver was performed. The lesser omentum was resected. HDL, hepatoduodenal ligament; IVC, inferior vena cava; CRS, cytoreductive surgery 
Table 1 Summary of the cases

\begin{tabular}{|c|c|c|c|}
\hline & Case 1 & Case 2 & Case3 \\
\hline Site of the primary tumor & Ascending colon & Cecum & Sigmoid colon \\
\hline $\begin{array}{l}\text { Time from the primary tumor resection to } \\
\text { peritoneal metastases (month) }\end{array}$ & 26 & 12 & Simultaneous \\
\hline $\begin{array}{l}\text { Time from the primary tumor resection to CRS } \\
\text { and HIPEC (month) }\end{array}$ & 32 & 17 & 13 \\
\hline Adjuvant chemotherapy after CRS and HIPEC & None & None & $\begin{array}{l}5-\mathrm{FU}+\mathrm{LV}+\text { bevacizumab } \\
8 \text { cycles }\end{array}$ \\
\hline Time from CRS + HIPEC to liver metastases (month) & 15 & 5 & 6 \\
\hline Chemotherapy before hepatectomy & $\begin{array}{l}\text { IRIS + bevacizumab } \\
12 \text { cycles }\end{array}$ & $\begin{array}{l}\text { FOLFOX + bevacizumab } \\
5 \text { cycles }\end{array}$ & - \\
\hline Time from CRS + HIPEC to hepatectomy (month) & 49 & 9 & 6 \\
\hline Operative procedure of hepatectomy & $\begin{array}{l}\text { Left hemihepatectomy } \\
\text { Partial resection of S5 }\end{array}$ & Posterior sectionectomy & $\begin{array}{l}\text { Left lateral sectionectomy } \\
\text { Partial resection of S5 and S8 }\end{array}$ \\
\hline Operative time (min) & 269 & 150 & 335 \\
\hline Blood loss (ml) & 530 & 233 & 250 \\
\hline Complications after hepatectomy & Chylous ascites & None & None \\
\hline Clinical outcome & No recurrence & No recurrence & Death in 16 months after hepatectomy \\
\hline
\end{tabular}

Abbreviations: CRC colorectal cancer, CRS cytoreductive surgery, HIPEC hyperthermic intraperitoneal chemotherapy, $S$ segment

diagnosis was well-differentiated tubular adenocarcinoma with K-RAS mutation, T4a, N0, stage IIB [21]. Twenty-six months after the operation, PM was detected and CRS (CC- 0 ) and HIPEC were performed 6 months after adjuvant chemotherapy. Her PCI score was 17/39. After surgery, she developed a surgical site infection and wound dehiscence. She was followed-up without adjuvant chemotherapy. Fifteen months after CRS and HIPEC, liver metastases to segments 2 and 5 were detected (Fig. 2) and systemic chemotherapy (IRIS + bevacizumab, 12 cycles) was initiated because the patient refused surgical treatment. Systemic chemotherapy was continued for 12 months, until discontinuation due to malaise and dizziness. Twenty-two months later, the liver tumor increased in size and dilatation of the peripheral bile duct of the tumor in segment 2 was observed. The patient accepted surgical treatment at that time, and she underwent left hemihepatectomy and partial resection of liver segment 5 . Operative time was $4 \mathrm{~h}$ and $29 \mathrm{~min}$, and her total blood loss was $530 \mathrm{~mL}$. Broadwide adhesion around the liver was identified and we carefully dissected adhering organs, which included the diaphragm, stomach, duodenum, jejunum, and colon (Fig. 3). It took $2 \mathrm{~h}$ and $34 \mathrm{~min}$ from the time of the skin incision to the initiation of liver transection. A small amount of chylous ascites were found in the abdomen during the surgery. The postoperative course was uneventful, except for the chylous ascites from the abdominal drain, which gradually subsided after implementation of a fat-restricted diet and diuretics. No recurrence was detected in the absence of adjuvant chemotherapy for 12 months after hepatectomy.

\section{Case 2}

A 57-year-old woman underwent curative laparoscopic ileocecal resection for cecum cancer. Pathological diagnosis was moderately differentiated tubular adenocarcinoma without K-RAS mutation, T3 N1, stage IIIB [21]. Twelve months after the operation, PM and bilateral ovarian metastases were detected and CRS (CC-0) and HIPEC were performed 5 months after adjuvant chemotherapy. The PCI score was $5 / 39$. The postoperative course was uneventful, and she was followed-up without adjuvant chemotherapy. Five months after CRS and HIPEC, liver metastasis to segment 6 was detected (Fig. 2) and systemic chemotherapy (FOLFOX + bevacizumab) was performed. After 5 cycles of chemotherapy over a period of 4 months, the size of the liver metastasis had decreased and no other metastasis or dissemination was detected. Surgical treatment was indicated and posterior sectionectomy of the liver [22] was performed. Operative time was $2 \mathrm{~h}$ and $30 \mathrm{~min}$, and her total blood loss was $233 \mathrm{~mL}$. Adhesion of the liver surface to the diaphragm and stomach was found, although it was relatively loose. It took $56 \mathrm{~min}$ from the time of the skin incision to the initiation of liver transection. The postoperative course was uneventful, and no recurrence was detected in the absence of adjuvant chemotherapy for 5 months after hepatectomy.

\section{Case 3}

A 38-year-old man underwent Hartmann's operation for the perforation of the sigmoid colon. Sigmoid colon cancer with PM was detected, and bilateral and diffuse CRLM were also diagnosed during the operation. Pathological 
a

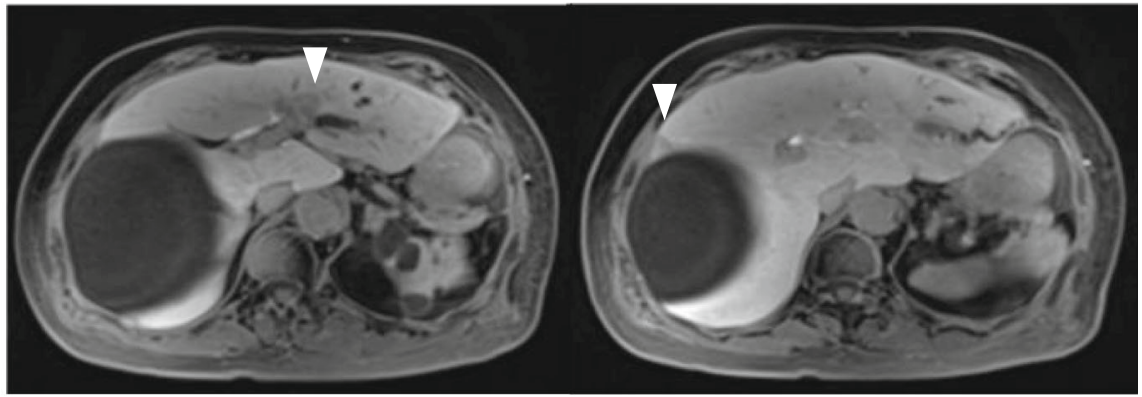

b

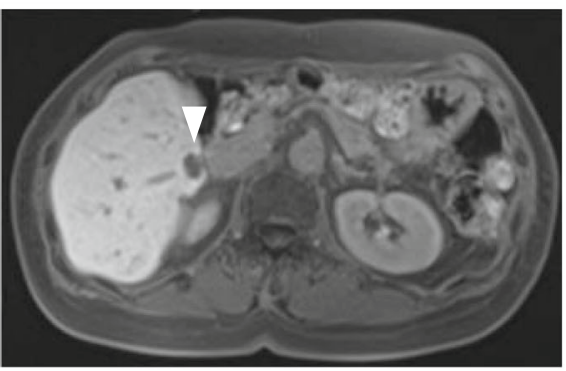

C

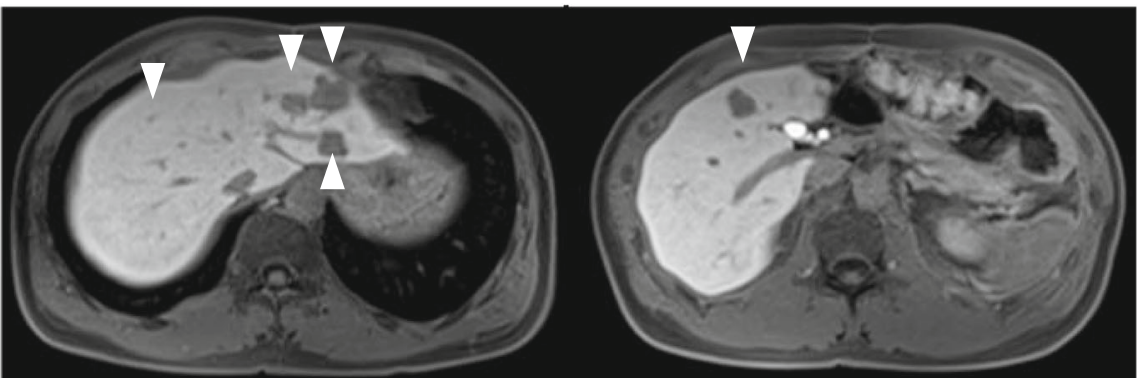

Fig. 2 The locations of liver metastases on MRI in the hepatocyte phase. The locations of the tumors are shown with the arrowhead. a Case 1. Liver metastases were detected in segments 2 and 5. b Case 2. Liver metastases were detected in segment 6. c Case 3. Liver metastases were detected in segments 2, 3, 5, and 8. MRI, magnetic resonance imaging

diagnosis was moderately differentiated tubular adenocarcinoma without K-RAS mutation, T4a N2, M1c, stage IVC [21]. FOLFOX + bevacizumab was performed for 10 cycles and discontinued because of drug-induced pneumonitis. After the second-line chemotherapy using 5$\mathrm{FU}+$ leucovorin (LV) was performed for 10 cycles, complete remission of liver metastases was achieved. CRS (CC-0) and HIPEC were performed 13 months after the primary tumor resection. The PCI score was $2 / 39$. The postoperative course was uneventful. Adjuvant chemotherapy using 5-FU + LV + bevacizumab was performed because the risk of recurrence was high. After 8 cycles of adjuvant chemotherapy, recurrence of liver metastases in segments 2, 3, 5, and 8 was newly detected (Fig. 2). Six months after CRS and HIPEC, he underwent left lateral liver sectionectomy [22] and partial resection of liver segments 5 and 8 . Operative time was $5 \mathrm{~h}$ and $35 \mathrm{~min}$, and his total blood loss was $250 \mathrm{~mL}$. The surface of the liver tightly adhered to the abdominal wall, diaphragm, stomach, duodenum, and colon, and we dissected them carefully without damage to other organs. It took $1 \mathrm{~h}$ and 37 min from the time of skin incision to the initiation of liver transection. Two months after the hepatectomy, metastases to the liver and lymph nodes were detected. Systemic chemotherapy was performed, but the cancer progressed gradually. The patient died 16 months after hepatectomy.

The clinical courses of the three cases are summarized in Fig. 4.

\section{Discussion}

CRS and HIPEC were first described in 1980 [23]. This procedure involves stripping of the diseased peritoneum 
a

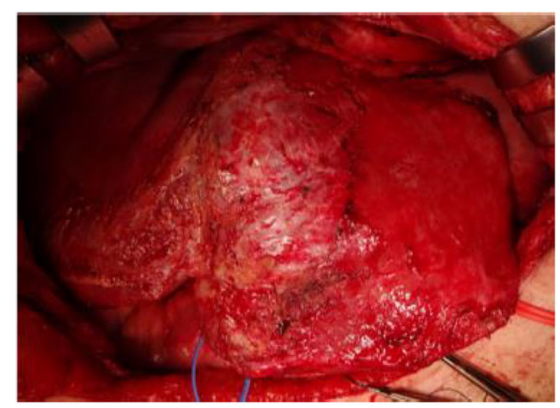

c

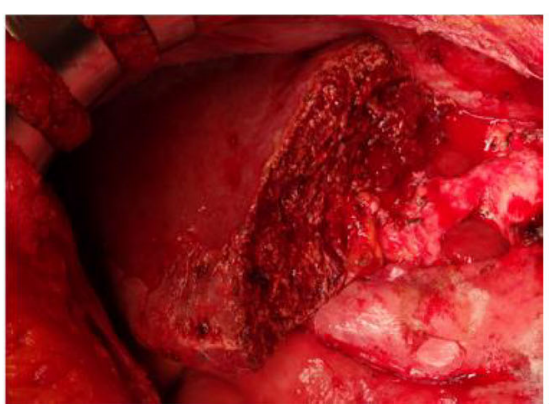

b
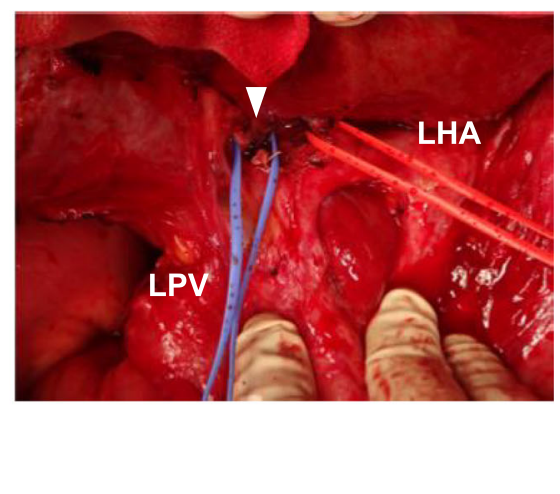

\section{(}


With improved prognosis, recurrence after initial CRS and HIPEC has recently been a topic of discussion [16]. Most cases of recurrence have been reported to be intraabdominal, with the liver being the second most frequent site of recurrence after the peritoneum. About $10-20 \%$ of patients develop liver metastases after CRS and HIPEC $[15,16]$. Although recent reports suggested that simultaneous hepatectomy for liver metastases with CRS and HIPEC could improve prognosis [26, 27], metachronous hepatectomy after CRS and HIPEC has been scarcely reported. Sánchez-Velázquez et al. reported a case of caudate lobectomy with inferior vena cava resection for liver metastasis from CRC following CRS and HIPEC for colorectal PM, and the patient showed no recurrence for 18 months after hepatectomy [28]. In the present study, we presented three cases of metachronous liver metastases from CRC treated by hepatectomy after CRS and HIPEC for PM. All hepatectomies were successfully performed, and no recurrence was detected in cases 1 and 2, although the observation periods were short. In case 3, liver metastases were diagnosed first; although complete remission was achieved once with systemic chemotherapy, early recurrence was found after hepatectomy for liver metastases. Case 3 showed synchronous presentation of hepatic metastases with a primary tumor, which was reported to be a risk factor for recurrence after CRLM resection, implying that the indication for CRLM resection after CRS and HIPEC should be carefully considered when making a decision about the procedure. However, recent advancement of multi-modality treatment for CRC revealed the efficacy of surgical resection even for metastatic lesions including liver, lung, and peritoneum [29, 30]. Considering these previous reports, surgical approach for liver metastasis after CRS + HIPEC might be justified for better prognosis, although curative and safe resection should be secured.

CRS procedures around the liver include peritonectomy of the bilateral diaphragm and hepatoduodenal ligament, lesser omentum resection, and ablation of the liver surface serosa; therefore, severe adhesion around the liver is expected during reoperation after CRS. In addition, intraabdominal chemotherapy, including HIPEC and early postoperative intraperitoneal chemotherapy, could enhance postoperative adhesion [24]. In the present three cases, hepatectomy was performed after prior CRS and HIPEC. Adhesion of surrounding organs to the liver surface was broadly observed because the peritoneum around the liver was completely stripped in the previous CRS. However, the adhesions could be dissected as in other abdominal surgeries in which the removal of the peritoneum was not aimed, and hepatectomy could be performed safely. This was probably because of the characteristics of peritoneal healing following a peritoneal injury. Fibrinolytic activity over the peritoneal surface is reported to decrease after damage to the peritoneum, leading to changes in the expression and synthesis of various cellular mediators and in the remodeling of connective tissues [31]. Thus, for patients with good performance status and with the ability to combat adverse events, hepatectomy for recurrences in the liver, even after previous CRS and HIPEC procedures, may be associated with long overall survival. However, owing to the shortness of the observational period in the present cases, further studies are needed to show the long-term outcomes of hepatectomy for liver recurrences after previous CRS and HIPEC. In addition, the optimal timing of hepatectomy for liver metastasis after CRS + HIPEC including the interval between liver metastasis and CRS + HIPEC and conversion from systemic chemotherapy should be investigated for more efficacious multi-modality treatment to advanced CRC.

\section{Conclusion}

In conclusion, three cases of hepatectomy for CRLM after CRS and HIPEC were reported in the present study. Although adhesion around the liver was severe and relaparotomy could have been difficult, the adhesions could be dissected safely. Hepatectomy for metachronous liver metastasis after CRS and HIPEC was feasible in specialized centers and could be considered as a multi-modality treatment option for advanced $\mathrm{CRC}$ recurrence.

\section{Abbreviations \\ CC: Completeness of cytoreduction; CRC: Colorectal cancer; CRLM: Colorectal liver metastases; CRS: Cytoreductive surgery; FU: Fluorouracil; \\ HIPEC: Hyperthermic intraperitoneal chemotherapy; LV: Leucovorin; \\ PCI: Peritoneal cancer index; PM: Peritoneal metastases}

\section{Acknowledgements}

None

\section{Authors' contributions}

$\mathrm{KI}$ and $\mathrm{NT}$ contributed to the study concepts and design. Kl, NT, Fl, FM, TKu, $\mathrm{YG}, \mathrm{TKi}$, and $\mathrm{HY}$ contributed to the data acquisition. $\mathrm{Kl}$ and $\mathrm{NT}$ contributed to the data analysis and interpretation. Kl, NT and NK contributed to the manuscript preparation. KI, NT, YG, and NK contributed to the manuscript editing. KI, NT, YG, and NK contributed to the manuscript review. All authors read and approved the final manuscript.

\section{Funding \\ None}

\section{Availability of data and materials}

The datasets used and/or analyzed during the current study are available from the corresponding author on reasonable request.

\section{Ethics approval and consent to participate}

The National Center for Global Health and Medicine Research Ethics Committee/Institutional Review Board approved this study.

\section{Consent for publication}

Consent for publication was obtained from all the patients described in this article. 


\section{Competing interests}

The authors declare that they have no competing interests.

\section{Author details}

'Hepato-Biliary-Pancreatic Surgery Division, Department of Surgery, National Center for Global Health and Medicine, 1-21-1 Toyama, Shinjuku-ku, Tokyo 162-8655, Japan. ${ }^{2}$ Department of Surgery, National Center for Global Health and Medicine, 1-21-1 Toyama, Shinjuku-ku, Tokyo 162-8655, Japan.

Received: 5 March 2019 Accepted: 5 June 2019

Published online: 13 June 2019

\section{References}

1. Koppe MJ, Boerman OC, Oyen WJ, Bleichrodt RP. Peritoneal carcinomatosis of colorectal origin: incidence and current treatment strategies. Annals Surg. 2006;243:212.

2. Jayne D, Fook S, Loi C, Seow-Choen F. Peritoneal carcinomatosis from colorectal cancer. Br J Surg. 2002;89:1545-50

3. Sadeghi B, Arvieux C, Glehen O, Beaujard AC, Rivoire M, Baulieux J, Fontaumard E, Brachet A, Caillot JL, Faure JL. Peritoneal carcinomatosis from non-gynecologic malignancies: results of the EVOCAPE 1 multicentric prospective study. Cancer. 2000;88:358-63.

4. Kobayashi H, Kotake K, Sugihara K. Outcomes of surgery without HIPEC for synchronous peritoneal metastasis from colorectal cancer: data from a multi-center registry. Int J Clin Oncol. 2014;19:98-105.

5. Shida D, Tsukamoto S, Ochiai H, Kanemitsu Y. Long-term outcomes after RO resection of synchronous peritoneal metastasis from colorectal cancer without cytoreductive surgery or hyperthermic intraperitoneal chemotherapy. Ann Surg Oncol. 2018;25:173-8.

6. Sugarbaker PH. Patient selection and treatment of peritoneal carcinomatosis from colorectal and appendiceal cancer. World J Surg. 1995;19:235-40.

7. Verwaal VJ, van Ruth S, de Bree E, van Slooten GW, van Tinteren H, Boot H, Zoetmulder FA. Randomized trial of cytoreduction and hyperthermic intraperitoneal chemotherapy versus systemic chemotherapy and palliative surgery in patients with peritoneal carcinomatosis of colorectal cancer. J Clin Oncol. 2003;21:3737-43.

8. Glehen $\mathrm{O}$, Kwiatkowski F, Sugarbaker $\mathrm{P}$, Elias $\mathrm{D}$, Levine $\mathrm{E}$, De Simone $\mathrm{M}$, Barone R, Yonemura Y, Cavaliere F, Quenet F. Cytoreductive surgery combined with perioperative intraperitoneal chemotherapy for the management of peritoneal carcinomatosis from colorectal cancer: a multiinstitutional study. J Clin Oncol. 2004:22:3284-92.

9. Verwaal VJ, Bruin S, Boot H, van Slooten G, van Tinteren H. 8-year follow-up of randomized trial: cytoreduction and hyperthermic intraperitoneal chemotherapy versus systemic chemotherapy in patients with peritoneal carcinomatosis of colorectal cancer. Ann Surg Oncol. 2008:15:2426-32.

10. Yan TD, Morris DL. Cytoreductive surgery and perioperative intraperitoneal chemotherapy for isolated colorectal peritoneal carcinomatosis: experimental therapy or standard of care? Ann Surg. 2008;248:829-35.

11. Elias D, Lefevre JH, Chevalier J, Brouquet A, Marchal F, Classe J-M, Ferron G, Guilloit J-M, Meeus P, Goéré D. Complete cytoreductive surgery plus intraperitoneal chemohyperthermia with oxaliplatin for peritoneal carcinomatosis of colorectal origin. J Clin Oncol. 2008;27:681-5.

12. Elias D, Gilly F, Boutitie F, Quenet F, Bereder J-M, Mansvelt B, Lorimier G, Dubè $P$, Glehen $O$. Peritoneal colorectal carcinomatosis treated with surgery and perioperative intraperitoneal chemotherapy: retrospective analysis of 523 patients from a multicentric French study. J Clin Oncol. 2010;28:63-8.

13. Cavaliere F, De Simone M, Virzi S, Deraco M, Rossi C, Garofalo A, Di Filippo F, Giannarelli D, Vaira M, Valle M. Prognostic factors and oncologic outcome in 146 patients with colorectal peritoneal carcinomatosis treated with cytoreductive surgery combined with hyperthermic intraperitoneal chemotherapy: Italian multicenter study SITILO. Eur J Surg Oncol. 2011;37: 148-54

14. Mirnezami R, Moran BJ, Harvey K, Cecil T, Chandrakumaran K, Carr N, Mohamed F, Mirnezami AH. Cytoreductive surgery and intraperitoneal chemotherapy for colorectal peritoneal metastases. World J Gastroenterol. 2014;20:14018.

15. Cashin PH, Graf W, Nygren P, Mahteme H. Cytoreductive surgery and intraperitoneal chemotherapy for colorectal peritoneal carcinomatosis: prognosis and treatment of recurrences in a cohort study. Eur J Surg Oncol. 2012;38:509-15.
16. Königsrainer I, Horvath P, Struller F, Forkl V, Königsrainer A, Beckert S. Risk factors for recurrence following complete cytoreductive surgery and HIPEC in colorectal cancer-derived peritoneal surface malignancies. Langenbeck's Arch Surg. 2013:398:745-9.

17. Abdalla EK, Vauthey J-N, Ellis LM, Ellis V, Pollock R, Broglio KR, Hess K, Curley SA. Recurrence and outcomes following hepatic resection, radiofrequency ablation, and combined resection/ablation for colorectal liver metastases. Ann Surg. 2004;239:818.

18. Adam R, Avisar E, Ariche A, Giachetti S, Azoulay D, Castaing D, Kunstlinger F, Levi F, Bismuth F. Five-year survival following hepatic resection after neoadjuvant therapy for nonresectable colorectal [liver] metastases. Ann Surg Oncol. 2001:8:347-53

19. Jacquet P, Sugarbaker P. Current methodologies for clinical assessment of patients with peritoneal carcinomatosis. J Exp Clin Cancer Res. 1996;15:49-58.

20. Jacquet $\mathrm{P}$, Sugarbaker $\mathrm{PH}$. Clinical research methodologies in diagnosis and staging of patients with peritoneal carcinomatosis. In Peritoneal carcinomatosis: principles of management. Springer; 1996:359-74.

21. Gospodarowicz MK, Brierley JD, Wittekind C. TNM classification of malignant tumours. UK: Wiley; 2017. p. 73-76.

22. Strasberg SM. Nomenclature of hepatic anatomy and resections: a review of the Brisbane 2000 system. J Hepatobiliary Pancreat Surg. 2005;12:351-5.

23. Spratt JS, Adcock RA, Muskovin M, Sherrill W, McKeown J. Clinical delivery system for intraperitoneal hyperthermic chemotherapy. Cancer Res. 1980;40:256-60.

24. Sugarbaker PH: Peritoneal carcinomatosis: natural history and rational therapeutic interventions using intraperitoneal chemotherapy. In Peritoneal Carcinomatosis: Drugs and Diseases. Springer; 1996: 149-168

25. Sugarbaker PH. Peritonectomy procedures. Ann Surg. 1995;221:29.

26. Maggiori L, Goéré D, Viana B, Tzanis D, Dumont F, Honoré C, Eveno C, Elias D. Should patients with peritoneal carcinomatosis of colorectal origin with synchronous liver metastases be treated with a curative intent? A casecontrol study. Ann Surg. 2013;258:116-21.

27. Kianmanesh R, Scaringi S, Sabate J-M, Castel B, Pons-Kerjean N, Coffin B, Hay J-M, Flamant Y, Msika S. Iterative cytoreductive surgery associated with hyperthermic intraperitoneal chemotherapy for treatment of peritoneal carcinomatosis of colorectal origin with or without liver metastases. Ann Surg. 2007;245:597.

28. Sánchez-Velázquez P, Moosmann N, Töpel I, Piso P. "En bloc" caudate lobe and inferior vena cava resection following cytoreductive surgery and hyperthermic intraperitoneal chemotherapy for peritoneal and liver metastasis of colorectal cancer. World J Gastroenterol. 2016:22:10249.

29. Gallagher DJ, Kemeny N. Metastatic colorectal cancer: from improved survival to potential cure. Oncology. 2010;78:237-48.

30. Van Cutsem E, Cervantes A, Adam R, Sobrero A, Van Krieken J, Aderka D, Aranda Aguilar E, Bardelli A, Benson A, Bodoky G. ESMO consensus guidelines for the management of patients with metastatic colorectal cancer. Ann Oncol. 2016;27:1386-422.

31. Cheong YC, Laird SM, Li TC, Shelton JB, Ledger WL, Cooke ID. Peritoneal healing and adhesion formation/reformation. Hum Reprod Update. 2001;7:556-66.

\section{Publisher's Note}

Springer Nature remains neutral with regard to jurisdictional claims in published maps and institutional affiliations.

Ready to submit your research? Choose BMC and benefit from:

- fast, convenient online submission

- thorough peer review by experienced researchers in your field

- rapid publication on acceptance

- support for research data, including large and complex data types

- gold Open Access which fosters wider collaboration and increased citations

- maximum visibility for your research: over $100 \mathrm{M}$ website views per year

At $\mathrm{BMC}$, research is always in progress.

Learn more biomedcentral.com/submission 